\section{Measuring ecosystem's response to climate change through sun induced fluorescence (SIF) in the Caatinga bioregion}

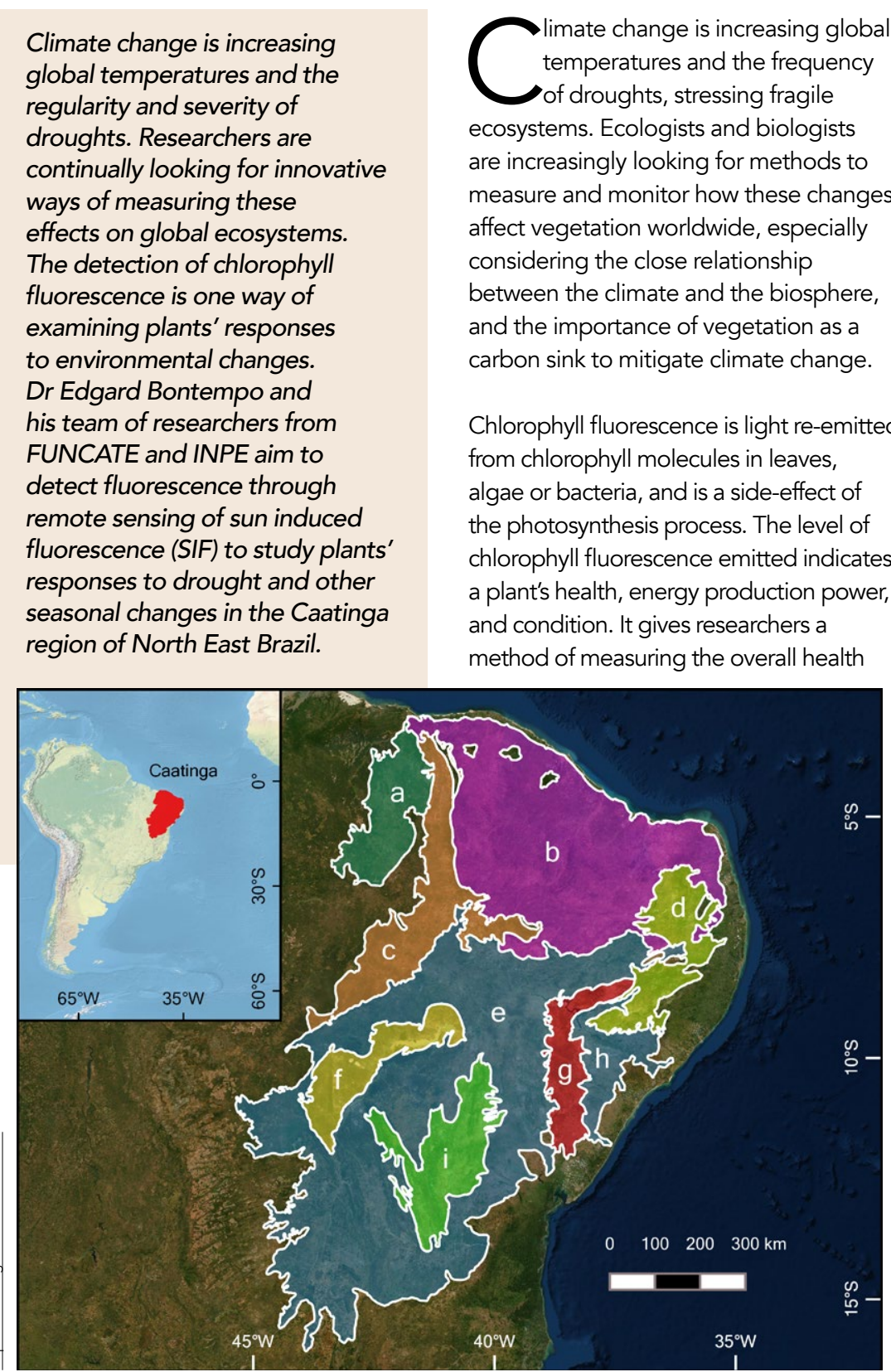

of plants within an ecosystem through climatic changes over time.

Fluorescence is traditionally measured on a small scale at the level of the individual leaf or plant. However, developments in remote sensing over the last 20 years have meant that measuring chlorophyll fluorescence can be done on a broader scale with drones, satellites, and the Sun Induced Fluorescence (SIF) method of measuring fluorescence emissions.

Dr Bontempo of the Brazilian FUNCATE and INPE institutes has used these new SIF techniques to document the effects Caatingal region in Nathons on the Caatinga region in North East Brazil over period of drought $\mathrm{Dr}$ Bontempo and his fellow researchers used this study to find new approaches to improve the interpretation of captured data, validate the efficacy of using SIF as a measure of plant and ecosystem health, and describe vegetation responses to environmental variation in the Caatinga region.

STUDYING VEGETATION CHANGE THROUGH SIF Chlorophyll fluorescence detection at the leaf level is well understood and has been studied for 90 years, allowing the measurement of the condition and productivity of vegetation in agricultural, genealogica, and ecological studies. The study of fluorescence has been traditionally
performed in carefully controlled

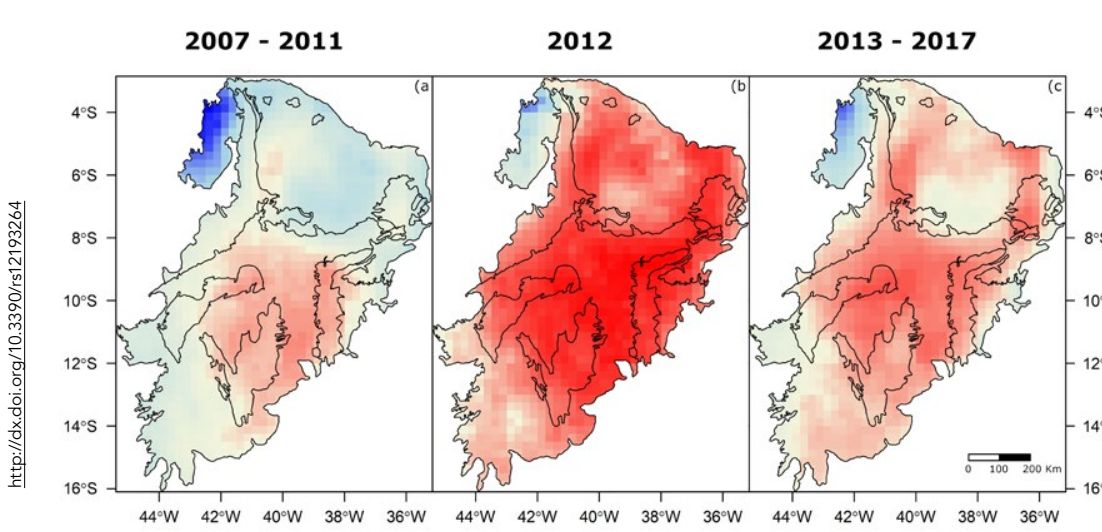

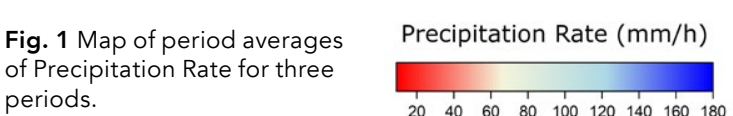

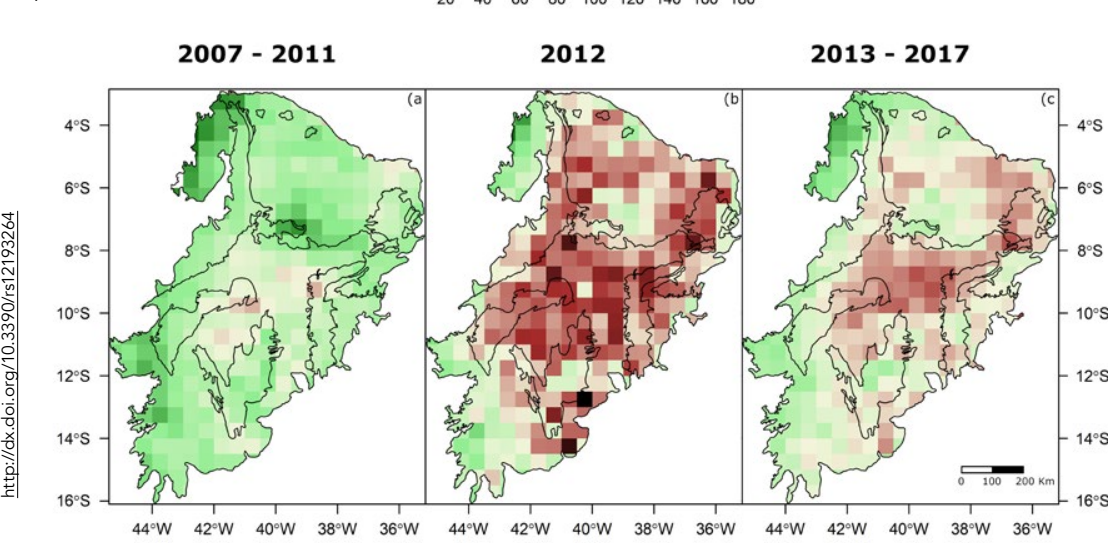

Fig. 2 Map of period averages of
Sun-Induced Fluorescence (SIF)
for three periods $\left(\mathrm{mW} \mathrm{m}^{-2} \mathrm{~nm}^{-1} \mathrm{sr}^{-1}\right)$

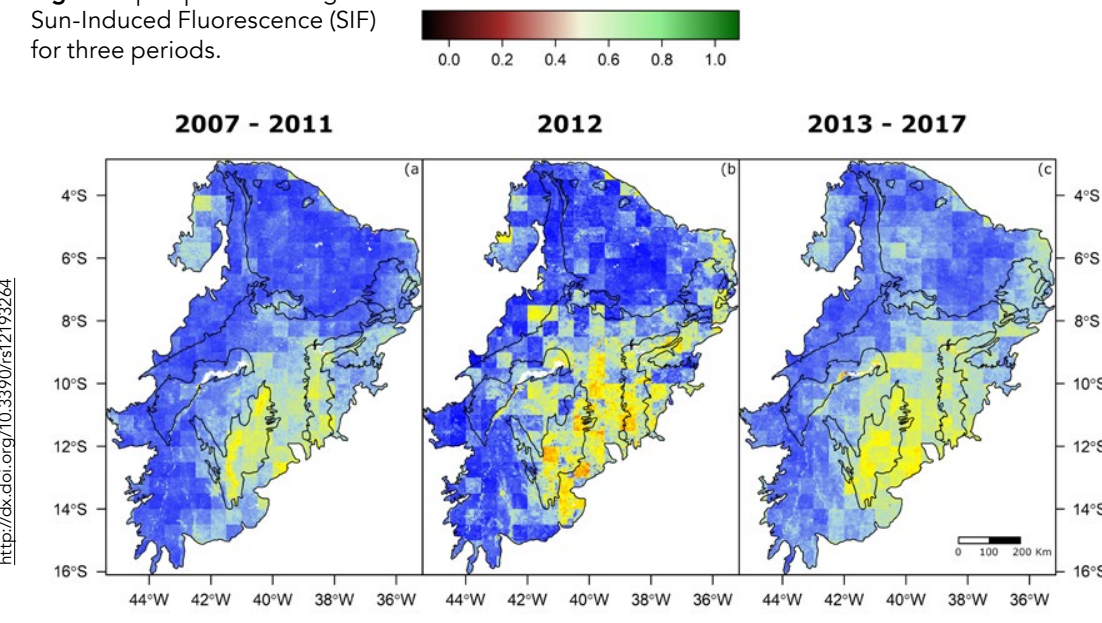

Fig. 3 Period averages of the
correlation between SIF and
NDVI for three periods Correlation between SIF Fr and NDVI (r.u.)

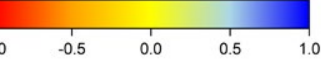

The level of chlorophyll fluorescence emitted indicates a plant's health, energy production power, and condition.

conditions with laboratory or fieldgrade fluorometers. The use of remote platforms like satellites, airplanes, and Unmanned Aerial Vehicles (UAV) to measure fluorescence is a recent development, which is understudied and retrieve accurate data from.
SIF is fluorescence data when sampled remotely with passive illumination. Ther chlorophyll fluorescence, including capturing data over large remote areas, which can be repeated across multiple than field studies. However, there are are many benefits in how SIF can capture still many difficulties in evaluating and finding meaning in ST data, ast remains primary reasons for the challenges in interpreting SIF data. The first is the use of natural sunlight, as there are so many variables such as atmospheric conditions and time of day. The second is the geometry between the leaves, the sensor (satellite), and the light source (sun). which can be very difficult to manage over a large area with mixed vegetation.

In Dr Bontempo's study, he used SIF data collected from the GOME-2 orbital satellite, a satellite initially designed for monitoring ozone levels in the atmosphere. The environmental indicators used in the study included surface metriols, and so

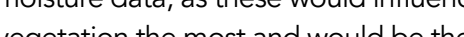
best climatic variable to set aginst the SIF data to infer the plants' responses.

Dr Bontempo's study developed and tested new approaches in interpreting SIF data to mitigate some difficulties using UAVs to capture fluorescence emissions. The three primary methods to achieve these included angular adjustments to relate to the sun's zenith angle, looking across the two spectrums in which fluorescence is emitted red and far-ed. Additionally, a normalised difference vegetation index (NDVI) - a measure of greenness traditionally utilised in remote sensing since the 1980 s was used in combination with SIF as These mod pied SIF mea-level studies. with the orignal, mere set aganst the with the original, decomposition, rank correlations tests, and linear mixed models.

\section{THE CAATINGA ECO-REGION} The Caatinga is a semi-arid region in the inhabitants. The area is characterised by heterogeneous vegetation and low levels of biodiversity relative to other areas in Brazil, such as the Pantanal and the Amazon. The heterogeneous nature of the vegetation, water-dependent seasonality, and recent extreme drought makes the Caatinga an ideal area for studying the efficacy of SIF in measuring and monitoring ecosystem health.

The Caatinga also has high levels of climatic unpredictability, with droughts 


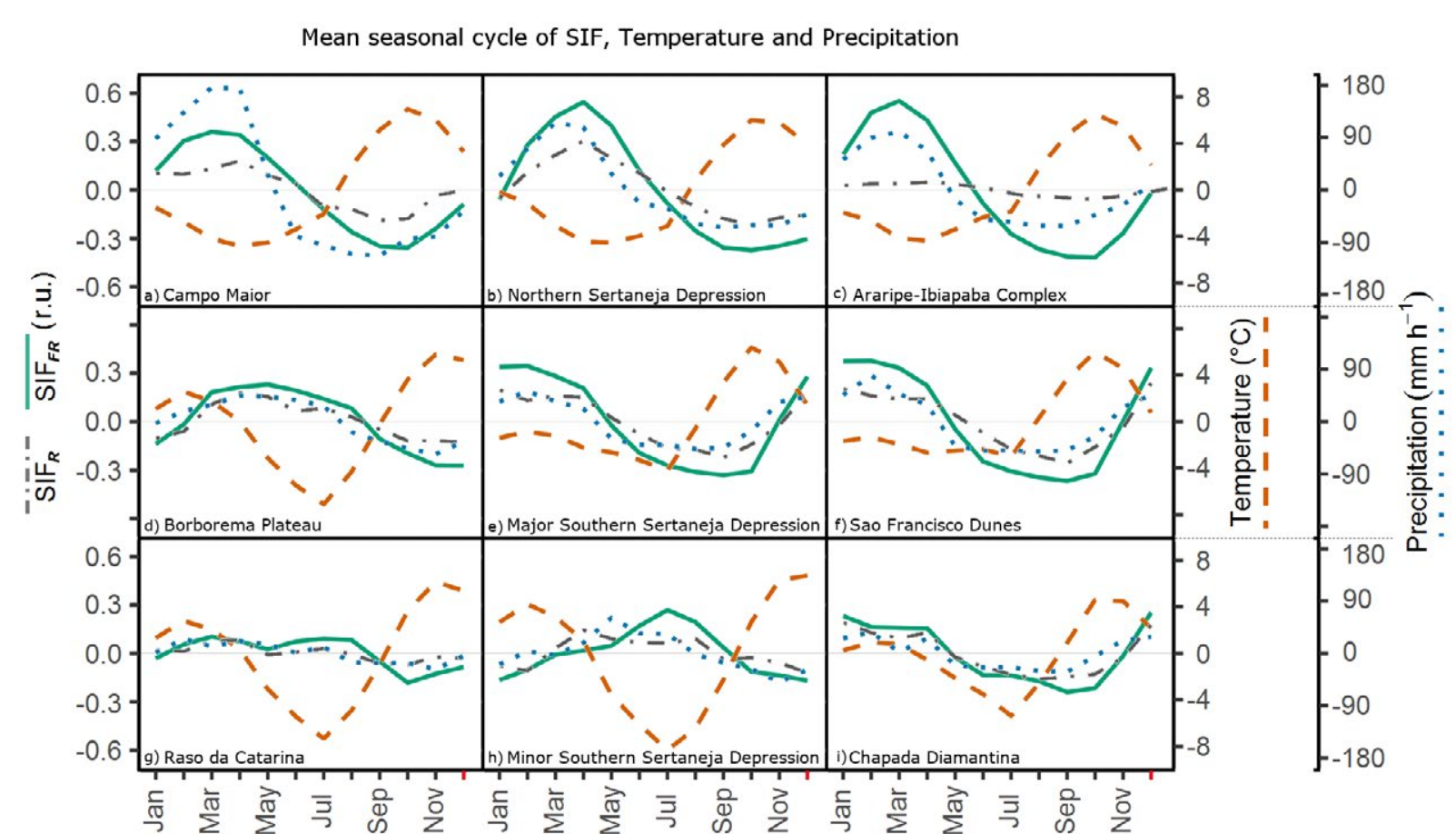

Fig. 4 Seasonal components of SIF, Temperature and Precipitation, from February 2007 to December 2017.

lasting from months to decades. The natural resources to exploit, has led to neglect of both the populace and the broader environment by the government and scientific research. Considering the level of endemic species and diversity, deserves further study, investment, and protection.

\section{PLANT RESPONSES}

TO CLIMATE CHANG

The results of this unique 11-year study showed that although data from SIF is complex, it is a good way of measuring plants' responses to climatic variation and droughts. The research demonstrated the value of SIF by

showing correlations This critical research from $D$

These new methods will inspire future such as higher definition romote sensing fluorescence detectors (for example, the European Space Agency FlEX mission a satellite designed explicitly for chlorophy fluorescence detection).

\section{A STUDY WITH FAR-REACHING} IMPLICATIONS

Nearch from Dr Bontempo shows how effective SIF is in detecting change. It is the first study that uses SIF in a semi-arid region and shows the

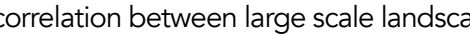

found that those maps of vegetation which did exist were not concurrent team was motivated to join a project to map deforestation and vegetation through the Amazon Fund. This would support conservation initiatives for gaps for future research.

This research will show the value of SIF, give insights into how to use SIF more effectively, and document the effects of climate variations on vegetation in fearch also advises future studies to precipitation, soil (a) temperature data The study found a substantial seasona difference in the level of fluorescence from the region's vegetation, which was pronounced further during a significan drought. These differences were show to be closely related to the different vegetation types within the Caatinga.

The methodology, in utilising the sun's zenith angle, the red and farred spectrums of fluorescence emissions and NDVIS, showed how remotely to help with the inder be manipulated SIF data and mediums of SIF collection from towers and drones, towers and drones,
in order to better climate change.

resilience to climate change). One of the most important findings was that areas with different vegetation types responded very differently to climatic changes. The importance of this revelation comes from its discovery through SIF data, with minimal data o the vegetation types in the area.

In the process of this research, $\mathrm{Dr}$ Bontempo and his team found that there was a profal through their research and mapping types in the region, with funding from the REDD+ framework from UNFCCC subsistence farmers and fill knowledge

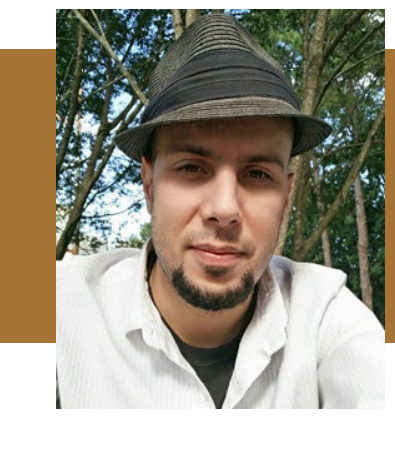

\section{Behind the Research}

\section{Dr Edgard Bontempo}

E: edgard.silva@funcate.org.br T: +5512 3925-1336 W: http://biomas.funcate.org.brit W: http:///www.fundoamazonia.gov.br/pt/projeto/Monitoramento-Ambiental-dos-Biomas-Brasileiros/
Research Objectives

Dr Edgard Bontempo and his team investigate the effects of climate change on an ecosystem by studying sun induced fluorescence.

\section{Detail}

\section{Address}

UNCATE, Geoprocessing Department

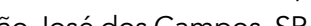

Brazil

Dr Edgard Bontempo is a Brazilian biologist. He graduated rrom the Federal University of Viçosa (2006), and obtained his M.Sc. (2009) and Ph.D. (2012) from Hokkaido University (Japan). He specialises in plant ecology and is interested in studying plant community responses to the environment and particularly to climate change.

Funding Development (CNPq), The Amazon Fund and FUNCATE

Collaborators

(University of Nebraska - Lincoln) - Druani Gava (NPSA,

- Druiz O. (Universtat de València)

\section{References}

Bontempo, E., Dalagnol, R., Ponzoni, F., and Valeriano, D. Responses at the Caatinga of Northeast Brazil. Remote Sensing, 12(19), 3264. Available at: https://doi.org/10.3390/ rs12193264

\section{Personal Response}

Do you believe the increased investment for creating "ecological maps" and other further research in the Caatinga region will have a beneficial knock-on effect

II Yes, since these maps can be used to help public policy planning and also since they raise awareness about the ing wic value of the local ecosystems to the


(2020). Adjustments to SIF Aid the Interpretation of Drough understand the effects of climate change on vegetation over different temporal and spatial scales, and to make better ecological predictions. Furthermore, hot have focused on the Caatinga region projects will encourage further research in the area. This should heighten ecosystem protection and restoration, and improve ecosystem services, Caating residents.

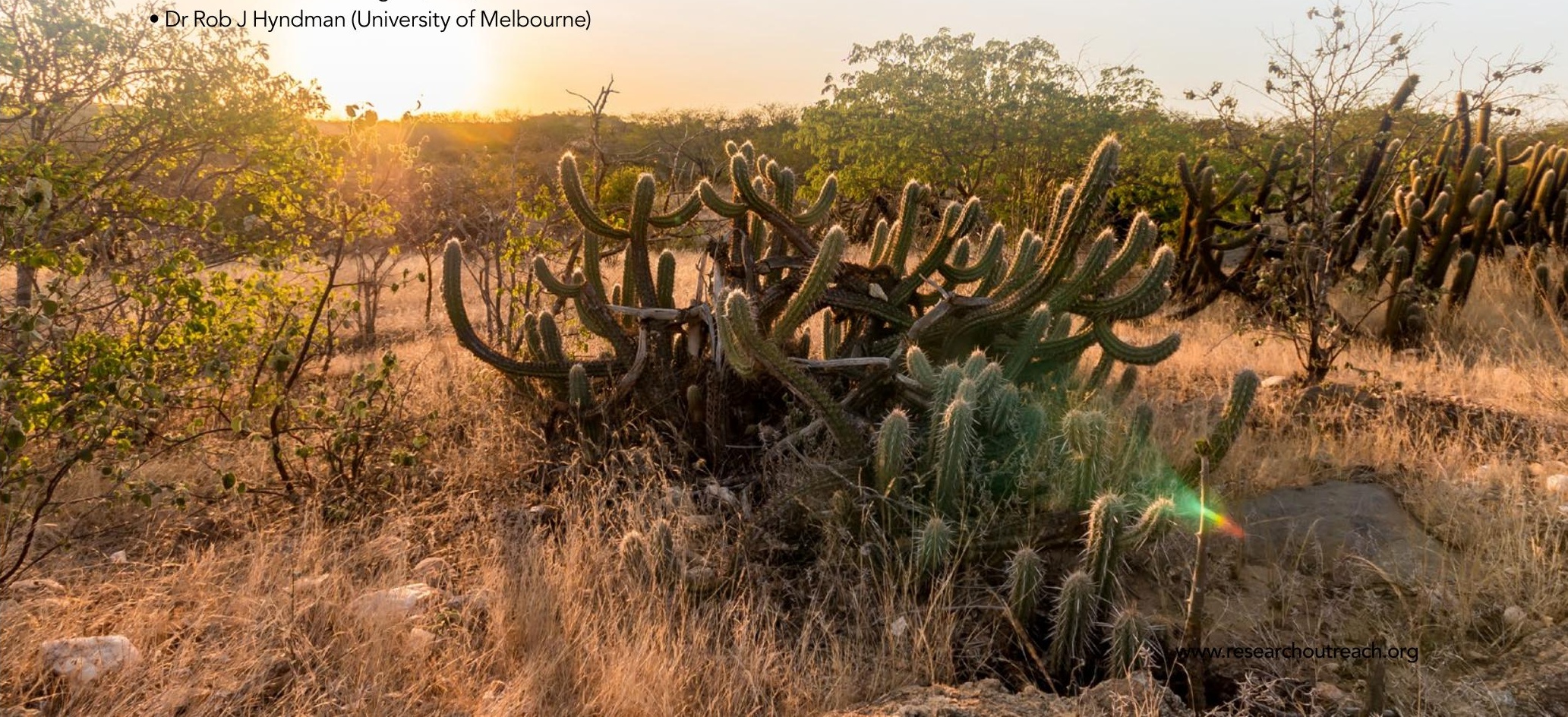

